\title{
DESAFIOS CULTURAIS DA COMUNICAÇÃO À EDUCAÇÃO
}

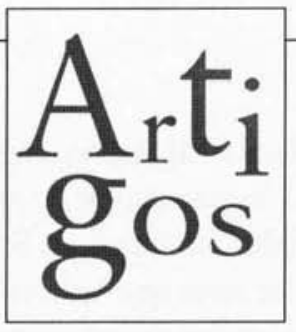

internacionais

\section{Inovações no Campo da Comunicação colocam desafios para a Educação que não devem ser menosprezados quando se pretende a construção da cidadania}

A ausência tanto do mundo dos meios massivos - exceção feita ao cinema, porque é arte - quanto do mundo da educação na Lei da Cultura é o indício mais forte da pertinaz esquizofrenia de que padecem a concepção e as políticas oficiais de cultura. A mais ingênua explicitação dessa esquizofrenia correu por conta de um membro da Comissão Nacional de Televisão da Colômbia, quando perguntado acerca do que pensava sobre a última programação de Señal Colombia' ${ }^{1}$, respondeu esse senhor que era perfeita: educação pela manhã e cultura à tarde!

$\mathrm{Na}$ Colômbia do fim do século, parece que as melhores relações entre cultura e educação seriam aquelas que não lhes permitam encontrar-se. Já as relações de ambas com a televisão não podem ser mais anacrônicas e instrumentais: a TV não é vista como um meio para fazer/criar cultura, mas apenas para transmitir, difundir, divulgar. Para o brilhante Ministério da Cultura, os meios massivos de comunicação continuam sendo qualquer coisa menos cultura, embora seja pelo rádio e, sobretudo, pela televisão que se efetuam, hoje em dia, algumas das mais profundas transformações na sensibilidade e na identidade das maiorias. Por isso, não é de estranhar que nós, os colombianos, não tenhamos direito a um canal cultural durante todo o dia, mas sim a apenas alguns programas soltos e às três horinhas de La Franja ${ }^{2}$ que, aliás, se transmite num horário inconveniente para os colombianos que, no dia seguinte, têm de madrugar para ir ao trabalho. Para o Ministério da Educação, o que acontece na cultura é assunto de outros e o que acontece na mídia também, isso sem ignorarmos a retórica vazia sobre a modernização tecnológica da escola, ou esse angu de programação televisiva que se faz passar por educativa.

Pouco importa se a concepção de cultura que guia os currículos e os ensinamentos escolares é tão radicalmente anacrônica - e socialmente perigosa - que nela não cabem senão as artes e as letras, ficando de fora a ciência e a tecnologia. Os países ricos que inventem, que criem e que a nós nos deixem continuar copiando e aplicando.

\section{O AUTOR}

Jesús Martín-Barbero

Filósofo. Assessor do Instituto de Estudos sobre Culturas e Comunicação da Universidade Nacional, Colômbia.

1. Canal cultural e educativo estatal da Colômbia, criado em 1968, reformado em 1992, passando a denominar-se Canal 3, mais para ver. Em 1995 lançou-se como uma alternativa para o público com nova programação e nova imagem corporativa Señal Colombia, talento no ar. (www.scripto.com.co/inravision/lasenal.htm) (N. Ed.)

2. La Franja é o nome dado ao horário destinado ao conjunto de programas do Ministério da Cultura no canal educativo Señal Colombia. Esse horário diário estende-se das 21 horas à meia noite. (N. Ed.) 
Para o Ministério das Comunicações - com exceção do esforçado e desvalorizado trabalho da Divisão de Comunicação Social - a cultura parece não ter nada que ver com o desenvolvimento tecnológico dos meios; o que, no caso, importaé a divisão política e economicamente adequada das permissões de transmissão. O mesmo acontece em relação à educação: que pode ter a ver o avançadíssimo e riquíssimo mundo das telecomunicações com a nossa atrasada e paupérrima educação? Não obstante, o que o país está jogando aí, na ausência de políticas conjuntas de Cultura/Comunicação/Educação, é sua própria viabilidade como nação, tanto política quanto cultural, tanto social quanto laboral, já que tudo isso passa pela necessidade de que o ecossistema comunicacional se articule e se organize com as dinâmicas da cultura e da educação. Isso, porém, não é possível a partir de políticas governamentais que são conjunturais e imediatistas; o que se necessita são políticas de Estado de longo alcance. Dentre os múltiplos desafios que verdadeiras políticas de Estado carregam consigo, num campo de tal envergadura, vou referir-me apenas a uma, configurada pelos desafios culturais apresentados pela comunicação para a educação. Para prevenir contra as decepções, aviso que no segmento deste artigo não se devem esperar fórmulas políticas, pois a única maneira de escapar à acumulação conjuntural $\mathrm{e}$ fragmentária de diagnósticos está em arriscar-se a formular problemas.

\section{DESENCONTRO DA EDUCAÇÃO COM O PAÍS}

Comecemos pelo princípio: antes de falar do papel dos meios de difusão na escola, ou de como introduzir cultura e educação nesses meios, vamos ter a coragem de colocar o problema fundamental: o que é que tem de mudar no sistema educacional - do Ministério às faculdades de educação, do ensino fundamental até a universidade - para que a escola se comunique com o país? Ou, de outro modo: o que tem de mudar no sistema educativo para que este possa incumbir-se de mostrar o que a Colômbia está vivendo e sofrendo, produzindo e criando; para que a escola possibilite às crianças e aos jovens uma compreensão do seu país que os capacite para ajudar a mudá-lo?

Contrariamente aos que vêem nos meios de comunicação e na tecnologia de informação uma das causas do desastre moral e cultural do país, ou seu oposto, uma espécie de panacéia, de solução mágica para os problemas da educação, sou dos que pensam que nada pode prejudicar mais a educação que nela introduzir modernizações tecnológicas sem antes mudar o modelo de comunicação que está por debaixo do sistema escolar.

O modelo predominante é vertical, autoritário na relação professor-aluno e linearmente seqüencial no aprendizado. Introduzir nesse modelo meios e tecologias modernizantes é reforçar ainda mais os obstáculos que a escola tem para se inserir na complexa e desconcertante realidade de nossa sociedade. Ao colocar como ponto de partida as mudanças que são necessárias à escola para que ela possa interagir com o país e não simplesmente para a utilização dos meios de comunicação, estou enfrentando um mal-entendido que o sistema escolar não parece interessado em desfazer: a obstinada crença de que os problemas da escola podem ser solucionados sem que se transforme o seu modelo comunicativo-pedagógico, isto é, com uma simples ajuda de tipo teconológico. E isso é um auto-engano. Enquanto permanecer a verticalidade na relação docente e a seqüencialidade no modelo pedagógico, não 
haverá tecnologia capaz de tirar a escola do autismo em que vive. Por isso, é indispensável partir dos problemas de comunicação antes de falar sobre os meios.

\section{PAPEL DA INFORMAÇÃO E DO CONHECIMENTO}

Falar de comunicação significa, em primeiro lugar, reconhecer que estamos numa sociedade em que o conhecimento e a informação têm tido um papel fundamental, tanto nos processos de desenvolvimento econômico quanto nos processos de democratização política e social.

A informação e o conhecimento são hoje o eixo central do desenvolvimento social, $\mathrm{e}$ isso ainda mais nos países do chamado Terceiro Mundo, em países como a Colômbia, nos quais uma industrialização precária não impede que estejamos entrando numa sociedade cuja competitividade produtiva depende mais da informação e do conhecimento do que das máquinas, mais da inteligência do que da força.

Isso está implicando uma transformação profunda das condições de trabalho, tanto nas indústrias de ponta como na automobilística, ou mesmo em indústrias tão antigas como a indústria têxtil. As funções cumpridas pelos operários neste tipo de indústria estão mudando radicalmente: da relação entre a força da mão-de-obra com a energia produzida pelas máquinas estamos passando a um novo tipo de relação, mediada, cada vez mais, pela in- formação e pela automatização dos processos.

Também no campo político, como tem sido demonstrado pelo Processo $8.000^{3}$, as coisas estão mudando de forma muito mais acelerada do que supõem os politicólogos deste país, cuja imensa maioria tem desconhecido a trama comunicativa da política e relegado a ação dos meios televisivos a uma função puramente instrumental. Entre outras coisas, o Processo 8.000 tem servido para que o país comece a perceber que a informação e a visibilidade têm hoje um papel constitutivo, tanto na formação do discurso político (que não é só o discurso dos políticos) como na própria ação política. Isso quer dizer que a informação passou a ter um papel tão estratégico na política que, sem ela, dificilmente teria sido possível desenvolver-se um julgamento da corrupção dos políticos e da política. Papel fundamental tanto por seus aspectos positivos quanto negativos, tais como a transformação de jornalistas em juízes que abusam do poder da informação para condenar ou absolver, prejudicando, às vezes irreparavelmente, as pessoas e o país.

Mas é preciso reconhecer igualmente que sem essa informação - às vezes mal-usada - não teria existido o Processo 8.000. Portanto, o ponto de partida para se pensar as relações da educação com a comunicação está aqui: na centralidade que o conhecimento e a informação têm ainda em países como o nosso, nos quais existem outras necessidades estruturais, que consideramos básicas, como as da moradia e saúde para as maiorias. Essa é a trágica peculiaridade desses países, que são atravessados pelas transformações da comunicação e da informação enquanto a divisão social cresce e a precária classe média sofre uma forte crise, tudo isso afetando seu sistema

3. O Processo 8.000 foi o processo no qual a Fiscalia General de la Nación (Procuradoria Geral da Nação) investigou o presidente Samper e outros políticos do Partido Liberal que receberam dinheiro do cartel de narcotraficantes de Cali para a eleição presidencial. O Processo durou dois anos e culminou com a prisão de grande número de políticos do PL. (N.Ed.) 
produtivo, político e educativo.

Desgraçadamente, algumas dessas transformações vieram aumentar a brecha entre países ricos e países pobres, e entre pobres e ricos de um mesmo país, não só no que diz respeito a bens materiais como a bens simbólicos.

Há uma grande diferença entre as pessoas que podem estar conectadas com a Internet, beneficiando-se de uma grande quantidade de informações, de experimentação, de conhecimentos ou experiências estéticas e a imensa maioria excluída, desligada desse mundo de bens e experiências. Mas, não podemos permitir que nos baste a constatação e o lamento. Precisamos compreender como essa mesma sociedade dividida está sendo transformada pela centralidade das tecnologias e dos sistemas de comunicação.

\section{ECOSSISTEMA COMUNICATIVO}

Para enfrentar esse desafio, devemos estar conscientes de dois tipos de dinâmica que movem as mudanças na sociedade de que falamos. Num primeiro movimento, o que aparece como estratégico, mais do que a intervenção de cada meio, é a aparição de um ecossistema comunicativo, que está se transformando em alguma coisa tão vital como o ecossistema verde, ambiental.

A primeira manifestação e materialização do ecossistema comunicativo é a relação com as novas tecnologias - desde o cartão que substitui ou dá acesso ao dinheiro, até as grandes avenidas da Internet - com sensibilidades novas, muito mais claramente visíveis entre os mais jovens. Eles têm maior empatia cognitiva e expressiva com as tecnologias e com os novos modos de perceber o espaço e o tempo, a velocidade e a lentidão, o próximo e o distante. Trata-se de uma experiência cultural nova, ou, como chamou Walter Benjamin, um sensorium novo. Novos modos de perceber e de sentir; uma nova sensibilidade que, em muitos aspectos, se choca e rompe com o sensorium dos adultos.

Um bom campo de experimentação dessas mudanças e de sua capacidade de distanciar os jovens de seus próprios pais está na velocidade e na sonoridade. Não apenas na velocidade dos automóveis, mas também na das imagens, na velocidade do discurso televisivo, especialmente na publicidade e nos videoclipes e na velocidade dos relatos audiovisuais. $\mathrm{O}$ mesmo acontece com a sonoridade, a maneira como os jovens se movem entre as novas sonoridades: essas novas articulações sonoras que, para a maioria dos adultos, marcam a fronteira entre a música e o ruído, são, para os jovens, o começo de sua experiência musical.

Uma segunda dinâmica, que faz parte desse novo ecossistema no qual vivemos, e que é a dinâmica da comunicação, liga-se ao âmbito dos grandes meios, ultrapassando-os porém. Ela se concretiza com o surgimento de um ambiente educacional difuso e descentrado, no qual estamos imersos. Um ambiente de informação e de conhecimentos múltiplos, nãocentrado em relação ao sistema educativo que ainda nos rege e que tem muito claros seus dois centros: a escola e o livro.

As sociedades centralizaram sempre o saber, porque o saber foi sempre fonte de poder, desde os sacerdotes egípcios aos monges medievais ou, atualmente, aos assessores dos políticos. Dos mosteiros medievais às escolas de hoje, o saber conservou esse duplo caráter de ser, ao mesmo tempo, centralizado e personificado em figuras sociais determinadas.

A essa centralização, que implicava a circunscrição do saber a alguns lugares por onde 
circulava legitimamente, correspondiam personagens que detinham o saber, tal como os sacerdotes, até a reforma protestante, que ostentavam o poder de ser os únicos com capacidade para ler e interpretar o livro dos livros, a Bíblia.

Nós, pessoas que temos uma certa idade, passamos a maioria da nossa vida junto a uma igreja que falava latim, não só lingüística mas ideologicamente, isto é, que usava um discurso que tinha muito pouco a ver com o mundo das gentes e da cultura da cidade. Vem daí que uma transformação nos modos de circulação do saber é uma das mais profundas transformações que pode sofrer uma sociedade. E é aí que se situa a segunda dinâmica que configura o ecossistema comunicativo no qual estamos imersos: o saber é disperso e fragmentado e pode circular fora dos lugares sagrados nos quais antes estava circunscrito e longe das figuras sociais que antes o administravam.

A escola deixou de ser o único lugar de legitimação do saber, pois existe uma multiplicidade de saberes que circulam por outros canais, difusos e descentralizados. Essa diversificação e difusão do saber, fora da escola, é um dos desafios mais fortes que o mundo da comunicação apresenta ao sistema educacional.

Diante do professor que sabe recitar muito bem sua lição, hoje, senta-se um alunado que, por osmose com o meio-ambiente comunicativo, está embebido de outras linguagens, saberes e escrituras que circulam pela sociedade. Estes configuram os saberes-mosaico, como os chamou A. Moles, porque são feitos de pedaços, de fragmentos, o que não impede os jovens de ter, com frequiência, um conhecimento mais atualizado em física ou em geo- grafia que seu próprio professor. Isso está trazendo para a escola um fortalecimento do autoritarismo, como reação à perda de autoridade do professor, e não uma abertura para esses novos saberes. Em lugar de ser percebida como uma chamada a que se reformule o modelo pedagógico, a difusão descentralizada de saberes, possibilitada pelo ecossistema comunicativo, resulta no endurecimento da disciplina do colégio para controlar esses jovens, cada vez mais frívolos e desrespeitosos com o sistema sagrado do saber escolar.

\section{ESQUIZOFRENIA CULTURAL}

A partir destas duas dinâmicas: a de uma comunicação que se converte em ecossistema e a de uma forte diversificação e descentralização do saber, manifesta-se cada dia mais a esquizofrenia cultural de que sofrem hoje muitos cidadãos. Eles estão divididos entre aquele saber que lhes outorga um diploma oficial e lhes vai servir para a inserção nos modos habituais de ascensão social e de consecução de um status, e aquele outro saber que vai lhes servir para introduzir-se nas novas modalidades do sistema produtivo e inovador da sociedade. Saber este que coincide com aquilo de que a sociedade necessita para formar um cidadão capaz de autodeterminação e, por conseqüência, capaz de respeitar, conviver, harmonizar.

Infelizmente, nossa escola não é um espaço para a autodeterminação, conseqüentemente, não é um lugar para aprender a conviver e a harmonizar. Então, muito do saber difuso e descentrado que hoje circula na sociedade é a via de acesso a uma concepção mais democrática e eficiente, isto é, criadora e produtiva. Não estou desconhecendo as buscas pessoais de alguns professores e de algumas poucas instituições, estou falando do sistema educativo colombiano. 
Estou questionando uma escola que, no seu dia-a-dia, não educa democraticamente, por mais que dê cursos de educação cívica e de urbanidade. Não se aprende a ser democrático em cursos sobre a democracia, aprendese a ser democrático em famílias que admitem pais e filhos não-convencionais, em escolas que assumem a dissidência e a diferença como riqueza, com meios de comunicação capazes de dar, verdadeiramente, a palavra aos cidadãos.

Essa realidade produz uma defasagem muito grande entre o modelo de comunicação que vigora, hoje em dia, fora da escola, na sociedade da comunicação e o modelo ainda hegemônico de comunicação no qual se baseia o saber escolar. Qual seria, então, a reação do sistema educativo a esta experiência cotidiana da defasagem ou, em outras palavras, qual é a reação do sistema educativo da escola à brecha cada vez maior que existe entre a cultura da qual falam os professores e a cultura e sensibilidade apreendidas pelos alunos? É certo que isto não é um problema colombiano, é um problema que a própria Unesco não tem sabido enfrentar.

A Unesco, em boa quantidade de documentos, mostra a visão que continua prevalecendo e que é puramente instrumental: usar os meios televisivos para que mais gente possa estudar, porém estudar sempre a mesma coisa, ou seja, permitir, por exemplo, que os alunos vejam uma ameba numa tela gigantesca.

Estou fazendo uma caricatura, mas é fato que muitos dos documentos da Unesco perpetuam uma concepção incapaz de enfrentar os desafios culturais que o ecossistema comunicativo apresenta ao sistema educativo em seu conjunto. Eé por isso que nossas escolas continuam vendo nesses meios unicamente uma possibilidade de ilustrar o que se diz, de tornar menos aborrecida a lição, de amenizar algumas jornadas de trabalho, presas da inércia mais insuportável.

A atitude defensiva da escola e do sistema educativo estão levando-os a desconhecer ou disfarçar o fato de que o problema de fundo está no desafio que lhe é apresentado por um ecossistema comunicativo, do qual emerge outra cultura, outro modo de ver e ler, de aprender e de conhecer.

A atitude defensiva limita-se a identificar o melhor do modelo pedagógico tradicional com o livro e anatematizar o mundo audiovisual como o mundo da frivolidade, da alienação, da manipulação. Oxalá o livro fosse um meio de reflexão e de argumentação, mas, infelizmente, não o é. Como demonstra uma pesquisa da Universidad del Valle sobre hábitos de leitura e usos sociais da televisão, a imensa maioria das pessoas, de todas as classes sociais de Cali, identifica livro com dever escolar. Desta forma, uma vez terminado o período escolar da vida das pessoas, o livro deixaria de ter função.

Nossas escolas não estão sendo um espaço no qual a leitura seja um meio de criatividade e de prazer, mas sim o espaço no qual leitura e escrita se associam a tarefa obrigatória e chata. Castradora, inclusive.

Confundindo qualquer manifestação de estilo próprio com anormalidade ou com plágio, os professores sentem-se no direito de reprimir a criatividade. É o efeito dos hábitos e da inércia do ensino legitimado pelo modelo imperante de comunicação escolar.

Um jovem psicólogo que está fazendo tese sobre essa situação em Ciudad Bolivar, falavame acerca de sua triste descoberta: nos setores populares, o aprendizado da leitura, em vez de enriquecer, está empobrecendo o vocabulário das 
crianças, pois, ao tentar falar como se escreve, as crianças perdem grande parte da riqueza do seu mundo oral, inclusive sua espontaneidade narrativa. Ou seja, temos um sistema escolar que não só não ganha os jovens adolescentes para uma leitura e uma escrita criativas, como também ignora a existência de uma cultura oral que tem um idioma próprio, especialmente nos setores populares, o que não pode ser, de modo algum, confundido com analfabetismo. Essa é a outra cultura que desafia a escola e diante da qual a escola está tão desprovida de modos de interação e tão na defensiva quanto ocorre com o audiovisual.

\section{SOCIEDADE MULTICULTURAL}

O quadro não pode ser mais significativo: enquanto o ensino transcorre através do mundo do manual, o professor sente-se fortalecido; mas quando aparece o mundo da imagem, o professor perde a estabilidade, porque o aluno sabe muito mais e, sobretudo, porque maneja muito melhor a língua da imagem que o professor. Ante esse desmoronamento de sua autoridade frente ao aluno, o professor reage desautorizando os saberes que passam pela imagem. De outro lado, a oralidade cultural das maiorias também não cabe na escola, pois o mundo das piadas e das narrativas orais, o mundo dos provérbios e dos ditos populares, o mundo da música popular narrativa e do rap deslocam, também, a partir de suas próprias gramáticas, ritmos e prazeres, o ascetismo triste do autismo livresco.

A escola desconhece tudo o que de cultura se produz e transcorre pelo mundo audiovisual e pelo da cultura oral: dois mundos que vivem, justamente, do hibridismo e da mestiçagem, da mistura de memórias territoriais com imaginários deslocados. Enfrentemos o mal-entendido.

Reconhecer que vivemos numa sociedade multicultural significa não só aceitar as diferenças étnicas, raciais ou de gênero, mas também aceitar que em nossas sociedades convivem hoje indígenas da cultura letrada com outros da cultura oral e da audiovisual.

$E$ isto ocorre num sentido forte, pois essas três culturas configuram modos muito diferentes de ver e de pensar, de sentir e de fruir. E, ao reivindicar a existência da cultura oral e audiovisual, não estamos desconhecendo, de modo algum, a cultura letrada, mas sim desmontando a sua pretensão de ser a única cultura digna desse nome e o eixo cultural de nossa sociedade.

O livro continua sendo chave, pois nos abre para a primeira alfabetização, essa que deveria possibilitar o acesso não só à cultura letrada, mas também às múltiplas escritas que hoje conformam o mundo da informática e o audiovisual. O paradoxo é que, se o livro foi o eixo cultural das sociedades européias, não o foi nunca das sociedades latino-americanas, salvo como ingrediente de exclusão, muralha que deixava as maiorias fora da cidade letrada.

Aos que pensam que o mundo do livro está se acabando, pode-se dizer que nunca, neste país chamado Colômbia, publicouse tanto e leu-se tanto. O livro não está acabando e não vai acabar, ao contrário, cada vez se vão ler mais livros, incluídos aí os textos de multimídia, que não são o contrário do livro, mas sim outro modo de escrita e outro objeto de leitura.

O problema está em saber se a escola vai ser capaz de ensinar a ler livros não só como ponto de chegada mas também de partida para outra alfabetização, a da informática e das multimídias. Isso implica pensar se a escola está formando o cidadão que não só sabe ler livros, mas também noticiários de televisão e hipertextos informáticos. 


\section{FORMAÇÃO DE CIDADÃOS}

O cidadão de hoje pede ao sistema educativo que o capacite a ter acesso à multiplicidade de escritas, linguagens e discursos nos quais se produzem as decisões que o afetam, seja no campo de trabalho como no âmbito familiar, político e econômico. Isso significa que o cidadão deveria poder distinguir entre um telejornal independente e confiável e um outro que seja mero porta-voz de um partido ou de um grupo econômico, entre uma telenovela que esteja ligada ao seu país, inovando na linguagem e nos temas e uma telenovela repetitiva e simplória. Para tanto, necessitamos de uma escola na qual aprender a ler signifique aprender a distinguir, a tornar evidente, a ponderar e escolher onde e como se fortalecem os preconceitos ou se renovam as concepções que temos sobre política, família, cultura e sexualidade.

Precisamos de uma educação que não deixe os cidadãos inermes diante dos poderosos estratagemas de que, hoje, dispõem os meios de comunicação para camuflar seus interesses e fazê-los passar por opinião pública.

Para ajudar-nos a entender a profundidade da mudança cultural que hoje se dá no mundo da comunicação e da transformação tecnológica, Margaret Mead afirma: "Nosso pensamento ainda nos amarra ao passado, ao mundo tal como existia na época de nossa infância e juventude; nascidos e criados antes da revolução eletrônica, a maioria de nós não entende o que esta significa. Os jovens da nova geração, ao contrário, assemelham-se aos membros da primeira geração nascida em um país novo. Devemos aprender junto com os jovens a forma de dar os próximos passos" ${ }^{\prime 4}$.

Esta reflexão põe em cena um novo tipo de cultura. Aquela que é experimentada pela juventude contemporânea da revolução eletrônica e à qual Mead chama prefigurativa, por ser uma cultura que ainda não tem clara sua figura, tendo começado a emergir apenas nos finais dos anos 60 , caracterizando-se por ser aquela na qual os pares substituem os pais, instaurando-se assim uma ruptura sem correspondente na história. Esta ruptura representa não uma mudança de velhos conteúdos em novas formas ou vice-versa, mas sim uma transformação na natureza do processo: a aparição de uma comunidade mundial, na qual os homens de tradições culturais muito diferentes emigram no tempo, todos partilhando as mesmas lendas e sem modelos para o futuro. Um futuro apenas balbuciado pelos relatos da ficção científica, na qual os jovens encontram narrada sua experiência de habitantes de um mundo cuja complexa heterogeneidade "não se deixa expressar em seqüências lineares tais como as que eram ditadas pela palavra impressa"s. E que remete, por conseguinte, a um aprendizado fundado menos na dependência dos adultos que na própria exploração, feita pelos habitantes do novo mundo tecnocultural, da visão, da audição, do tato ou da velocidade.

Daí a importância estratégica que adquire hoje uma escola capaz do uso criativo e crítico dos meios audiovisuais e das tecnologias informáticas. Isso, porém, só será possível numa escola que transforme seu modelo (e sua práxis) de comunicação, istoé, que torne possível a passagem de um modelo centrado na sequiência linear - que encadeia de forma unidirecional graus, idades e grupos de conhecimentos - a outro descentralizado e plural, cuja chave é o encontro do palimpsesto e do hipertexto. En- 
tendo por palimpsesto esse texto no qual um passado que foi apagado emerge tenazmente, embora difuso, nas entrelinhas da escrita presente; e por hipertexto uma escrita não seqüencial, mas sim montagem de conexões em rede que, ao permitir/exigir uma multiplicidade de percursos, transforma a leitura em escrita.

Enquanto o tecido do palimpsesto nos põe em contacto com a memória, com a pluralidade de tempos carregada, acumulada por qualquer texto, o hipertexto remete à enciclopédia, às possibilidades presentes de intertextualidade $\mathrm{e}$ intermedialidade, duplo e imbricado movimento que está exigindo que substituamos o lamento moralista por um projeto ético: o do fortalecimento da consciência histórica, única possibilidade de uma memória que não seja mera moda retrô, nem evasão às complexidades do presente.

Só assumindo a tecnicidade midiática como dimensão estratégica da cultura é que a escola poderá inserir-se de novo nos processos de mudança atravessados pela nossa sociedade e interagir com os campos de experiência em que se processam essas mudanças.

Tais mudanças estão materializadas na desterritorialização/relocalização das identidades, hibridações da ciência e da arte, das literaturas escritas e das audiovisuais, reorganização dos saberes e do mapa dos ofícios. A partir de fluxos e redes através dos quais se mobiliza não só a informação como o trabalho, o intercâmbio e a concretização conjunta de projetos, de pesquisas científicas e de experimentações estéticas. Só encarregando-se dessas transformações, poderá a escola interagir com as novas formas de participação cidadã que o novo ambiente comunicacional abre, hoje, à educação.
Um dos maiores desafios que o ecossistema comunicativo faz à educação é: ou se dá a sua apropriação pelas maiorias ou se dá o reforçamento da divisão social e a exclusão cultural e política que ele produz.

Pois, enquanto os filhos das classes favorecidas entram em interação com o ecossistema informacional e comunicativo a partir de seu próprio lar, os filhos das classes populares - cujas escolas públicas não têm, em sua imensa maioria, a menor interação com o ambiente informático, escolas que são para eles o espaço decisivo de acesso às novas formas de conhecimento - estão ficando excluídos do novo espaço laboral e profissional que a cultura tecnológica propõe. Vemos, portanto, que há uma carência de demandas de comunicação no espaço educativo e que o acesso a elas não é democrático.

É a partir do entendimento de que há uma carência dessas demandas que se verá a necessidade de diferenciar a televisão educativa dos diversos modos de fazer educação pela televisão. Se é necessário pensar num tipo de presença da educação escolar nos meios televisivos, são igualmente ou mais necessárias outras modalidades de educação, entre as quais, para a Colômbia, destacaria duas: uma formação continuada de adultos, que os capacite justamente para colocar-se frente às novas linguagens e saberes que circulam na sociedade e diante dos quais a imensa maioria está desprovida de capacidade de leitura e de seu aproveitamento. Esse desconhecimento está agravando a exclusão social, começandose pela do trabalho. Em segundo lugar, um âmbito estratégico de educação de adultos que existe na Colômbia, e que é decisivo para nossas possibilidades de convivência. Este 
consiste na construção de uma história do país que articule suas múltiplas memórias, tanto étnicas como raciais, locais e de gênero, e em cuja construção audiovisual deveriam trabalhar os melhores historiadores, os melhores roteiristas e diretores de televisão, capazes de proporcionar-nos os elementos básicos com os quais construir identidades novas e, ao mesmo tempo, arraigadas, porém sem narcisismo, sem provincianismo, identidades que possam dialogar e atuar entre si e com o resto das identidades do mundo.

Entre a educação, entendida de forma ampliada pelo ecossistema comunicativo, e o lugar da escola, o chileno Martin Hopenhayn traduz em três objetivos básicos os códigos de modernidade ${ }^{6}$. Esses objetivos são: formar recursos humanos, construir cidadãos e desenvolver sujeitos autônomos. Em primeiro lugar, a educação não pode dar as costas às transformações do mundo do trabalho, dos novos saberes que a produção mobiliza, das novas figuras que recompõem aceleradamente o campo e o mercado das profissões. Não se trata de subordinar a formação à adequação de recursos humanos para a produção, mas sim que a escola assuma os desafios que as inovações tecnoprodutivas e relativas ao trabalho apresentam ao cidadão em termos de novas linguagens e saberes. Pois seria suicida para uma sociedade alfabetizar-se sem levar em conta o novo país que está aparecendo no campo da produção. Em segundo lugar, construção de cidadãos significa que a educação tem de ensinar as pessoas a ler $\mathrm{o}$ mundo de maneira cidadã.
A educação tem de ajudar a criar nos jovens uma mentalidade crítica, questionadora, desajustadora da inércia na qual as pessoas vivem, desajustadora da acomodação na riqueza e da resignação na pobreza.

É muito o que resta por mobilizar, a partir da educação, para renovar a cultura política de maneira que a sociedade não procure salvadores, mas sim crie sociabilidades para conviver, harmonizar, respeitar as regras do jogo cidadão, desde as do tráfego até as do pagamento dos impostos. E, em terceiro lugar, a educação é moderna na medida em que seja capaz de desenvolver sujeitos autônomos. Frente a uma sociedade que massifica estruturalmente, que tende a homogeneizar, inclusive quando cria possibilidades de diferenciação, a possibilidade de sermos cidadãos é diretamente proporcional ao desenvolvimento de sujeitos autônomos, isto é, de gente livre, tanto interiormente como em suas tomadas de posição.

Gente livre significa gente capaz de saber ler a publicidade e entender para que serve, e não gente que deixa massagear o próprio cérebro; gente que seja capaz de distanciar-se da arte que está na moda, dos livros que estão na moda, gente que pense com sua cabeça e não com as idéias que circulam ao seu redor. 
Resumo: Este artigo trata das preocupações de Jesús Martín-Barbero em relação à falta de compreensão na elaboração de políticas culturais na Colômbia, sobre como o campo da comunicação pode atuar frente aos desafios que a Educação tem de enfrentar para a formação de cidadãos livres e capazes de atuar de forma autônoma na sociedade. Ele discute as dificuldades e principalmente a incapacidade de a escola alterar sua relação com a produção e aquisição de conhecimento. O modelo de comunicação predominante na escola é vertical e autoritário na relação professor-aluno, e linear seqüencial no aprendizado, impedindo que se abra de maneira a enriquecer-se com as novas linguagens dos meios de comunicação. Ele também descarta a mera aquisição de equipamentos e tecnologias, por parte da escola, para a transposição ilustrativa dos conteúdos. Salienta que a escola precisa alterar suas formas de relacionamento com os jovens, com o conhecimento e com o conjunto da sociedade. Essas mudanças comportam entender a centralidade dos processos de comunicação ao que denominou ecossistema comunicativo para capacitar o jovem para uma mentalidade crítica, fazendo-o ler o mundo de maneira cidadã.

Palavras-chave: Colômbia, cidadania, escola, meios de comunicação, ecossistema comunicativo
Abstract: This article deals with Jesús MartínBarbero's concerns on the lack of understanding of the Colombian cultures policy elaboration, on how the communications field can perform when confronted with the challenges Education has to confront to form free citizens that are capable of performing autonomously in society. He discusses the difficulties and, most especially, the inability the school has in order to change its relationship with the production and acquisition of knowledge. The predominant communication model in school is vertical and authoritarian in the teacher-student relationship, while linear and sequential in learning, something that does not allowing it to be open in order to be enriched by the new means of communication languages. He also discards the school's merely acquiring equipment and technologies for the illustrative transposition of contents. The author stresses that the school needs to change the way it relates to the young people, to knowledge and to the society as a whole. These changes involve understanding the centrality the communication processes have which he denominated as the communicative ecosystem - to capacitate the young people to have a critical mentality, so they can read the world as participant citizens.

Key words: Colombia, citizenship, school, means of communication, communicative ecosystem 